http://economix.fr

Computer technology and probable job destructions in Japan: an evaluation 


\title{
Computer technology and probable job destructions in Japan: an evaluation*
}

\author{
Benjamin David ${ }^{\dagger}$
}

\begin{abstract}
This paper evaluates the risk of job destructions induced by computer technology in Japan. Relying on recent methodology, we find evidence that approximatively $55 \%$ of jobs are susceptible to be carried by computer capital in the next years. We also show that there is no significant difference on the basis of gender. On the contrary, non-regular jobs (those that concern temporary and part-time workers) are more vulnerable to computer technology diffusion than the others.
\end{abstract}

JEL Classification: C53, J21, O33.

Keywords: Computer technology, Japanese labor market, Automation, Random Forest

*We are grateful Professor Professor Valérie Mignon and Professor Ryo Kambayashi for helpful comments and suggestions.

${ }^{\dagger}$ EconomiX-CNRS, University of Paris Ouest, France. 


\section{Introduction}

In recent years, an important dissemination of computer and communication technologies has been observed in Japan and in other industrialized countries. This diffusion in economic activities is a broad and international movement with country specific timeline. According to Murata $(2010)$, this process begins in Japan in the 1950s via the acquisition of a US computer (Bendix G-15) by the Railway Technical Research Institute (1957) and continued through the 1960s by the introduction of second and third generation of computers. 11 These machines which were both imported and produced locally, were progressively dedicated to special purpose terminals in manufacturing, distributions and financial industries in the 1970s. During the 1980s, Japan undergone a massive development of office automation benefiting from the invention of Personal Computer (PC) and other specific programs such spreadsheets or work processors ${ }^{2}$ The spread of computers has continued until now and they are used every day in a large range of economic activities. In parallel, technical advance and deregulation policies have caused the emergence of networks supported by computer infrastructure. This concerns the use of the fax machine in the 1980s and above all the development of the Internet and mobile phone in the 1990s and 2000s. Networks have hugely modified the modalities of communication and reduced their costs. The actual situation is characterized by a massive access to these networks: $90 \%$ of Japanese people have an access to Internet and the ownership rate of mobile phone is equal to $120 \%$ (International Telecommunication Union, 2015).

Another aspect of the actual technological diffusion is the massive development of robotics that can be viewed as a component of the computer revolution (Spong et al. 2012) ${ }^{3}$ In this field, Japan is a key country both in terms of production and use to the point that it was labelled as « robot kingdom $\gg($ Schodt, 1988). Indeed, Japan has a long and fruitful history in this matter which began in the 1960s by the introduction of industrial robots dedicated to welding, assembling or painting, followed by the first mobile robots used in inspection, transport or spatial tasks in the 1980s (Kumaresan and Miyazaki, 1999). Production and use of robots continue at a large scale and were extented through the development of micro-robots and services robots.

\footnotetext{
1 The second generation of computers is characterized by the introduction of transistors and the third by the use of integrated circuits.

2 The first PC produced in Japan was the NEC PC 8001 (1979).

3 They argue that « The key element in the above definition is the reprogrammability of robots. It is the computer brain that gives the robot its utility and adaptability. The so-called robotics revolution is, in fact, part of the larger computer revolution».
} 
Illustrations of this trend are the actual efforts in the humanoid robotic field initiated by researchers of Waseda University who created Wabot 1 (1973) as well as other famous examples as ASIMO (Honda), Wakamaru (Mitsubishi), or Pepper (Aldebaran Robotics and Softbank). Data also show the importance of robotics diffusion in Japan. In 2013, this country has the second highest robot density in the world (323 units per 10000 workers) behind the Republic of Korea and has the most important robot density in the automotive industry with 1520 industrial robots per 10000 employees (International Federation of Robotics, 2014). $!^{4}$

All these digital devices share a common theoretical and technical background based on binary logic and basic electronic components such as transistor or microprocessor 5 Many scholars suggest that this set is not a simple group of incremental innovations but constitute a $\ll$ Technological Revolution $\gg$ or a $\ll$ technological-discontinuity $\gg($ Brynjolfsson and McAfee, 2011$)$ able to $\ll$ transform profoundly the rest of the economy $\gg$ and produce a $\ll$ new economic paradigm $\gg($ Perez, 2009).

Indeed, efforts of characterization of technologies in the literature suggest that innovations or interrelated cluster of innovations are not comparable in their scale and their degree. In this perspective, ICT can be viewed as a major technological set susceptible to produce large-scale impacts. In support of this vision, the literature on « General Purpose Technology » (GPT) (Bresnahan and Trajtenberg, 1995; Rosenberg and Trajtenberg, 2004) supposes that the most important technologies share the feature of generality. This crucial point was anticipated by Simon (1987) which stress that the higher is the level of generality of a technology, the higher is its potential because there is a very important number of possible applications. In the case of computer technology, the degree of generality is very high because all economic activities include information processing tasks.

This view is reinforced by the actual process of digitization of human activities which makes the amount of information available more and more important (« Big Data »). Furthermore, digitization is coupled with an impressive improvement of ICT capacities in information processing as well as in terms of transmission, storage and transformation of information (Nordhaus, 2007; Nagy et al., 2011; Koomey et al., 2010). Thus, it supposes that the field

\footnotetext{
4 Moreover, Japan not only employs robots but is a major producer with 127491 robots produced in 2014 of which 98882 were exported (Japan Robotics Association, 2015).

5 For this reason, we consider the following expressions as synonym: « computer technology $\gg$, « computer and communication technologies $\gg, \ll$ Information Technology (IT) $\gg, \ll$ Information and Communication Technologies $\gg(\mathrm{ICT})$.
} 
of application of computer technology is growing, a characteristic that could have notable effects on many economic matters. Among the possible consequences of ICT adoption, an important aspect is its potential destabilising impact on employment. Indeed, labour activities do not escape this trend of digitization: in production activities, there are many tasks consisting of manipulation of information but also that some other tasks can be modeled as information flows. For example, accounting calculations is a task which consists of transferring, stocking and transforming information. On the other hand, some physical activities such as assembly, construction, transport can also be represented as information. Material elements, the space in which they are situated, and movements can be defined as mathematical objects. From this perspective, these tasks are susceptible of being carried out by robots within computer programs representing physical objects, environment and motions in information way. With this in mind, it could be expected that a large number of tasks in a wide variety of fields could be given over to computers now and in the near future. This perspective constitutes a biggest challenge for modern economies. Acknowledging the importance of this topic, our aim in this paper is to investigate the impact of ICT on job destructions in Japan.

The perspective from which a growing share of tasks will be performed by computer capital has strong implications for several Japanese specific economic questions especially those pertaining to the labor market. Among these issues, we can mention the ageing process sustained by gains in longevity, while life expectancy is already one the highest in the world, and low immigration flows. Even if this process concerns several countries in Europe (Germany, France) or in Asia (Korea, China), it is important to stress that «Japan has the most rapidly aging population in the world » (IMF, 2013). On the supply side of the labor market, significant consequences of this evolution are the massive reduction of the overall labor-force, or a dependency ratio reduction in the coming years and decades. A possible response face to this scenario is to call to the technological solution. Growth of ICT capital stock could contribute to maintain the level of production and to help in the care of elderly people. On the demand side, we note that the Japanese labor market has experienced the introduction of more flexibility from the 1980s. This situation originates in the labor law reform in a context of assetinflated bubble economy collapse (Asao, 2011). The system characterized by job rigidity and wage flexibility (shūshinkoyō) has progressively left space for a growing number of non-regular jobs which represent roughly twenty millions people (Statistics Bureau, 2015). It is important to underline that if computer technology will replace workforce, it could do it differently according 
to the type of employment. Indeed, it is possible that computer technology destroys more easily non-regular employment either because dismissals are facilitated by legal disposition or because computer technology realizes rather tasks typically carried by non-regular workers. Inversely, if computer and communication tools threaten regular jobs, we can expect that the share of non-regular workers in overall active population increases significantly, thus profoundly affecting the structure of Japanese workforce. We also note that the computer revolution could have notable effects on other questions such as the participation of women in the workplace or could significantly modify the $\ll$ return to education $\gg$.

Turning to methodological issues, in order to assess the potential risk for Japanese workers associated with the diffusion of computer technology, we use Career matrix data from the Japan Institute for Labour Policy and Training (JILPT) and we build a training sample containing occupations without doubt automatable and other occupations that could be considered as nonautomatable. With this sample, we estimate a model explaining the probability of computerisation by the differential dotation in non-automatable skills. Estimation is achieved by using the $\ll$ Random Forest $\gg$ algorithm, which builds several uncorrelated decision trees from bootstrap samples from the training set and averages the results to obtain the final estimation. Then, by using our estimates and data from the Population Census (2010), we evaluate the number of jobs threatened by technology and we study the distribution of the probabilities by gender and type of employment.

Our results suggest that a large share of jobs could be performed by computer system in the coming years. More precisely, according to our estimates, one half of Japanese jobs are susceptible to be destroyed by computer technology. However, this global result masks differential effects according to the kind of workers since non-regular workers seem to be more exposed. On the contrary, we don't find results differentiated by gender. The rest of this paper is organized as follows. Section 2 briefly reviews the literature. Section 3 presents the methodology. Section 4 presents the results and section 5 concludes.

\section{Literature review: employment and com- puter}

A vast literature exists on the link between technology and employment, dating at least from classical economists such as Ricardo (1821) or Marx (1867). In this field, a recurrent question concerns the capacity of technology to re- 
place workers in economic activities. The possibility of the realization of this capital/labor substitution may be interpreted from the economic perspective by the following alternative: compensation theory or « technological unemployment $\gg($ Keynes, 1930).

The first approach refers to the fact that there are « compensation mechanisms that are triggered by technical change itself and which can counterbalance the initial labor saving impact of process innovation $\gg$ (Vivarelli, 2011) ${ }^{6}$ In this perspective, technology is not a serious threat to employment level but it could produce a qualitative shift in jobs. Under technological pressure, some tasks are no longer carried out by workers whilst other appear because of new activities. The second view is more pessimistic because it supposes that even if there are some compensation mechanisms, a part of the workforce replaced by technology doesn't find new jobs and contributes to « technological unemployment $\gg$. In this perspective, there is an inequality between the number of jobs destroyed and the number of jobs created.

Recently, this recurrent question has been raised again due to the diffusion of IT which seems capable of performing an ever-increasing share of tasks traditionally carried out by workers. In the recent literature, a major theoretical and empirical contribution in the understanding of the relationship between computer technology and the evolution of the distribution of occupations was made by Autor et al. (2003). They have developed an equilibrium model («task model $\gg$ ) in which producers use two types of inputs: routine and non-routine labors.7 They suppose that the first kind of labor input is perfectly substitutable by computer capital while the second constitutes a complement. The driving force of the model is the fall in prices of computer capital which produces differential evolution of each type of labor. Autor et al. (2003) provide econometrical evidences to support their model. A very similar study was written by Maurin and Thesmar (2004) who bring empirical arguments in favor of this hypothesis in France. Goos and Manning (2007) have extended this approach by showing that the non-routine tasks are mainly located in the top and the low level of wage distribution which can explain the polarization of the labor market observed in the UK. Many other works confirm the task-based polarization hypothesis for several economies such as Goos et al. (2009) or Autor and Dorn (2013).

With regard to the Japanese economy, Ikenaga (2009) uses the same frame-

\footnotetext{
[6]Vivarelli (2011) identify six types of compensation mechanisms.

7 Each input is an aggregate. Routine tasks are composed of routine cognitive tasks and routine manual tasks. Non-routine tasks can be non-routine analytic tasks, non-routine interactive tasks or non-routine manual tasks.
} 
work as Autor et al. (2003) and shows that since the 1990s, labor input of knowledge-intensive non-routine analytic tasks and low-skill non-routine manual tasks is growing, whereas, at the same time labor input of routine manual tasks has declined. In addition, Ikenaga identifies a complementary relationship between ICT capital and workers who carry out non-routine analytic tasks and a substitution trend with workers engaged in routine tasks. Ikenaga and Kambayashi (2010) also pay interest to the evolution of the input share of each type of tasks on the basis of a specific measure of « task intensity $\gg$ in each occupation. Their analysis suggests that there is a longterm increase in non-routine task input and a long-term decrease in routine tasks between 1960 until 2005. In addition, they found a positive correlation between the average wage in an occupation and the routine cognitive task input, and a negative correlation with routine manual task input.

Recently, Frey and Osborne (2013) have renewed the analysis of the exposure of workers faced with recent technological diffusion. A starting point of their approach is that the identification between non-routine tasks and low susceptibility to automation is called into question by the improvements of computer tools in the fields of machine learning and mobile robots. Indeed, non-routine tasks can also be carried out by computer capital. A famous example is the autonomous driverless cars, now in development (but operational), and nonetheless considered as a good example of non-automatable tasks by Autor et al. (2003) (cited by Brynjolfsson and McAfee (2011)). On the basis of expert opinions and relying on the computer science literature, Frey and Osborne (2013) go beyond the distinction routine tasks/non-routine tasks and propose that computerisation ${ }^{8}$ has strong limitations in perception and manipulation tasks, creative intelligence tasks, and social intelligence tasks. By using $\mathrm{O}^{*} \mathrm{NET}$ and SOC databases (from the US department of labor), the authors, helped by a panel of computer scientists, consider 70 occupations which are without doubt automatable or not in the next years. For example they consider that the cashier occupation is automatable, while childcare worker occupation is non-automatable. Then, they construct a probabilistic classification model with this training sample. The dependent variable is the probability of computerisation and the explicative variables are nine variables that representing the three $\ll$ bottlenecks $\gg$. They use this estimated model to predict the probabilities of automatization of the 702 occupations of their database. Then, they evaluate the number and the

$\sqrt[8]{6}$ Frey and Osborne $(2013)$ define Computerisation as follow: « We refer to computerisation as job automation by means of computer-controlled equipment $\gg$. To avoid unpleasant repetitions, we also use the usual term of $\ll$ automation $\gg$. 
distribution of jobs by sector now threatened by computer capital. Their results suggest that « 47 percent of total US employment is at risk $\gg$ (by considering a threshold of probability equal to 0.7 ).

In the present paper, we aim at implementing a similar analysis about Japanese labor market by assessing the share of jobs which could be threatened by computer technology over the next few years. This approach is justified by the fact that the results obtained by Frey and Osborne (2013) for the United States are not fully transposable to the case of the Japanese labor market. Indeed, there are some differences in industry and occupational structures between these two countries. Industries have not the same weight in each economy and occupations are partially different (follows that US and Japanese classificatiosn are not the same). We note, for instance, the existence of Japanese specific occupations such as kimono dressing instructor, sushi chef, pachinko employee, Juku teacher, administrative scrivener and some differences in occupations which have not the same valuations of skills (Ikenaga and Kambayashi, 2010).

On the other hand, Japan is a country where the technological issue is particularly interesting. Even if the spread of computer devices is an international dynamic, there are country specific characteristics. As discussed above, Japan has a high level of technology diffusion and it is a major producer of innovations. If computer technology has a significant impact on the structure or on the level of employment, we can expect that it will be particularly important in this country, in particular due to the development and the dissemination of robots.

\section{Methodology}

\subsection{Data}

The first step of our analysis is to constitute a training sample with which we build our prediction model. The purpose is to select occupations, which can be undoubtedly, in the current state, performed or not by computer capital. We also need some information about the levels of skills required to perform each occupation.

For that purpose, we use data from Career matrix, a database created by the JILPT containing 499 occupations based on the Classification of Oc- 
cupations for Employment Services (ESCO). It contains 35 variables that describe the level of different skills necessary for each occupation. These values are defined on the basis of surveys and range between 0 and 5, 0 being the lowest value and 5 the maximum value. Firstly, we select 61 occupations similar or very close to Frey and Osborne (2013) selection (which is itself based on computer science expert opinions). In order to expand our sample and ensure robust estimation, we add other automatable occupations identified on an empirical basis. This means that they are now subject to automation process or that a technology in an advanced development stage is susceptible to replace workers in these occupations. For example, we include in this sample the occupation « Train Driver $\gg$ because there are already automatic trains in running in Japan. Finally, the training sample considered in this study contains 69 occupations representing roughly 14\% of those of Career Matrix (tables 3, 4).

The second step in the constitution of our training sample is to select explanatory variables that determine the probability of automation. The baseline model supposes there are three limitations to automation: perception and manipulation tasks, creative intelligence tasks, and social intelligence tasks. Unfortunately, Career matrix doesn't contain variables for representing perception and manipulation tasks and creative intelligence tasks.

In order to overcome this problem, we create appropriate dummy variables for the two categories without data. Precisely, we define a dummy variable $\ll$ manual dexterity $\gg$ to reflect perception and manipulation tasks and two other to represent creative intelligence tasks: « Fine Arts $\gg$ and $\ll$ Originality $\gg$. We prefer to create dummies and only three variables to reduce the risk to assign subjectively values between 0 and 5 for the other variables. For example, the occupation of surgeon takes a value of 1 to signify that it requires high level of manual dexterity, while the occupation of lawyer takes a value of 0 to signify the inverse. We consider that this approach is a convenient tradeoff between the accounting of important variables and the risk of subjective assignation.

To represent social intelligence tasks, we select, in Career Matrix, the following five variables: « Coordination $\gg, \ll$ Persuasion $\gg, \ll$ Negotiation $\gg$, «Instructing $\gg$ and $\ll$ Service orientation $\gg$. Lastly, by examining variables contained in Career Matrix, we select another variable that seems impossible for the moment to automatize: « Judgment and decision making ». We call this task: Appreciation tasks. We present all data in table 5 . 


\subsection{Random Forest}

We aim to compute the probability of automation of occupations on the basis of the different dotations in non-computerisable tasks inputs by using the methodology of Frey and Osborne (2013): (i) considering a training sample of occupations which could be considered as clearly automatable or not, (ii) we build a model with this subsample, (iii) and we finally predict the probability of automation of all occupations. In this perspective, we have constituted a training sample as described in section 3-1. For the estimation, we rely on the « Random Forest $\gg(\mathrm{RF})$ algorithm!? a very useful method from machine learning framework.

The use of RF instead of a standard method requires explanation. In these kind of situation, when we consider a binary dependent variable, it is usual in applied economics to use logistic regression. However, in this case, for technical reasons, this seems impossible. Indeed, as suggested by Peduzzi et al. (1996), it is necessary to have at least 10 Events Per explanatory Variables (EPV) in order to perform logistic regression. Below this threshold, there are important risks of non-convergence, loss in terms of accuracy, or no normality of regression coefficients. In our case, we have 69 observations in the learning sample including 33 events (i.e. when the probability of automation is equal to one) and 10 explanatory variables $(\mathrm{EPV}=3.3)$. Another potential difficulty is the correlation between several explanatory variables. For example, the persuasion and negotiation variables are highly correlated $(\mathrm{r}=0.8)$. In front of these problems, it seems difficult to expand the size of the learning sample or to remove some variables just on a subjective basis.

Initially, for simplicity and to circumvent these technical problems, we have been interested in using regression trees ${ }^{10}$, specifically CART algorithm (Breinhan et al., 1984), a simple nonparametric method consisting in splitting the subspace of predictors in different regions and model the response of the dependent variable as a constant in each region.11 The main advantages of this approach are that no assumption on the functional form to linking the variables is required (that allows taking into account non-linearity), it produces easily readable results and it can avoid the multicolinearity problem between the variables in Career Matrix.

\footnotetext{
9For estimation, we use R Package randomForest version 4.6-10 (Liaw and Wiener. 2002). We consider $\mathrm{a} \ll$ forest $\gg$ containing 100 trees. We doesn't need more iterations because the study of the execution of the algorithm shows that the Mean Square Error (MSE) stabilizes around 40 trees.

10 Given the particular structure of data $(y=1$ or $y=0)$, we could use classification tree but we would a more nuanced view. By using regression tree instead, we could get all values between 0 and 1 .

11 CART part of the "Top 10 Algorithm in data mining" (Wu et al. 2008).
} 
However, regression trees, although being a very compelling method, suffer from a major drawback: instability (Breiman, 1996). If there is a small modification of the dataset, results will be altered substantially, constituting a key issue in terms of results'robustness. To overcome this major drawback, we rely here on another approach. Specifically, in order to stabilize trees and improve the accuracy of estimation, various methods have been developed, such as « bagging $\geqslant 2^{12}($ Breiman, 1996$)$ and $\ll$ Random Forest $\gg($ Breiman, 2001). We use the latter approach because this is a simple method that has interesting theoretical properties.

RF has three main components: tree (1), randomization (2) and bagging (3). The first step is to consider a bootstrap sample $b$ of the training data (one third of the sample is left out) and construct a tree (1). The difference with CART is that at each node $p$, we select randomly several variables for each node (2) and we split the node in two child nodes, by considering the variable $k$ and the split point $s$, that produce the best binary partition in terms of minimization of the residual sum of squares. Formally, the aim is to minimize the sum of squared errors from the two regions ( $R 1$ and $R 2$ ):

$$
\min _{k, s}\left[\min _{c 1} \sum_{x_{i} \in R_{1}(p, k, s)}\left(y_{i}-c_{1}\right)^{2}+\min _{c 2} \sum_{x_{i} \in R_{2}(p, k, s)}\left(y_{i}-c_{2}\right)^{2}\right]
$$

The best $\ll$ response $\gg$ in each $m$ region $\left(\hat{c}_{m}\right)$ is equal to the average value of the dependent variable. Since it is a regression tree, it is recommended that the number of $k$ randomly selected variables is equal to the following floor function $\left\lfloor\frac{K}{3}\right\rfloor$ (Hastie et al. 2009$)$ where $K$ denotes the number of explanatory variables. The third step is to repeat this procedure on $B$ bootstrap samples (3) and average the results of prediction to obtain the final estimation. It is important to stress that unlike CART, there is not $\ll$ pruning $\gg$ of the estimated tree ${ }^{13}$ At each step, the tree is constructed until it reaches its maximum size defined in advance. This procedure is summarized in figure 1 .

RF has several advantages, in addition to those generally associated with CART. First, using this method, we lose the possibility to summarize the estimation in a simple tree because with each bootstrap sample we estimate a new tree, but we eliminate the main problem of the instability of the results. Second, RF benefits from the randomization process because it allows to construct $\ll$ de-correlated trees $\gg$ which in turn lead to reduce the variance of the estimated model. Third, RF is a powerful method which performs

12 Bagging refers to $\ll$ Bootstrap AGGregatING $\gg$.

13 In CART, « Weakest Link Pruning » is used. 
Figure 1: RF Algorithm

a-Consider a $b$ bootstrap sample from the original data.

b-At each node, select randomly several splitting variables c-Split current node into two child nodes

Repeat steps a, b, c until the tree reaches a maximum size

NODE

TREE

Repeat steps 1 and 2 on B bootstrap samples

Average predictions

well when the sample has limited size and even if the number of observations is lesser than the number of predictor variables ${ }^{14}$. Lastly, $\mathrm{RF}$ permits also to compute a value which provides information on the importance of the variables in the estimation by using the $\ll$ Mean Decrease in Accuracy(MDA) $\gg$ criteria. For that purpose, we consider the Out-Of-Bag (OBB) sample, ie data that are not used for constructing the $b$ tree, and proceed as follows:

- Compute the error of a $b$ tree on its OBB sample.

- Permute randomly the value of the variable $k$ from the training sample and compute new OBB error.

- Average all the OBB errors to obtain the MDA (the value is normalized by standard deviation).

The underlying idea of this algorithm is to detect if the permutation involves a decrease in the accuracy of the model. If a variable is not important the decrease will be weak while it will be significant if a variable is important.

\section{Results}

\subsection{General results: classification of occupations}

Before commenting and studying the probabilities of computerisation and their economic implications, it is necessary to evaluate the accuracy of our model. A simple approach is to check how many predictions of the adjusted model are correct by looking at the confusion matrix (not reported here). If we consider a standard threshold of 0.5 for assigning a class to each occupation, the estimated model achieves accurate prediction in approximately

${ }_{14}^{14}$ See examples in Verikas et al. (2011). 
$88 \%$ of cases.

A more efficient measure of accuracy in classification problems is the Area Under Curve (AUC) that corresponds to the evaluation of the area situated under the Receiving Operating Curve (ROC). This tool enables to situate the quality of a classifier over two references, a perfect and a random classifier which have respectively an AUC value of 1 and 0.5. The model considered in our analysis has a value of AUC equal to 0.955, suggesting that it has a very good level of performance that allows us to have a relative confidence in the probabilities computed 15

Application of the RF algorithm permits to obtain a probability of automation for all occupations considered (see tables 7 to 21 in appendix). Given that there are 499 occupations, we cannot comment precisely all the results, but we could give an overview of the findings by selecting the top ten, bottom ten and some intermediate occupations (table 1). As shown, in the top 10 occupations, there are only occupations that require high level of creativity, manual dexterity or social intelligence. This is reflected in the variable importance measure that highlights the significant weight of the variables $\ll$ originality $\gg$ and $\ll$ manual dexterity $\gg, \ll$ instructing $\gg$ and $\ll$ negotiation $\gg$ in the estimation (table 6 in appendix).

Logically, occupations in the bottom ten are poorly endowed in non computerisable skills. A part of results is plausible with, for example, the probable disappearance of mail deliverer or cashier occupations. On the contrary, some occupations such as model or truck driver is difficult to appear as risky because no replacement process has now began.

\subsection{Detailed results}

Beyond the results by occupation, it is very interesting to draw lessons at different economic levels. Our aim is to study the number, the distribution and the properties of the jobs which could be destroyed by computer devices in the next years. The drawback is that Career matrix contains data on skills by occupation but no information on the number and the characteristics of workers who perform each occupation. To alleviate this problem, we rely on the data of the last population census (2010) that provides detailed information on the number, the type of employment and the gender of people which perform each job.

Our strategy is to construct a new data set combining interesting information from these two sources. Since Population Census considers only 232 occupations, we include all Career Matrix occupations in population cen-

15 Note that Frey and Osborne (2013) model has AUC equal to 0.894. 
Table 1: Overview of results

\begin{tabular}{lc}
\hline Top 10 occupations & Probability \\
\hline \hline Speech therapist & 0.014 \\
Lawyer & 0.019 \\
Stylist & 0.021 \\
Classical Musician & 0.025 \\
Theatre Decorator & 0.025 \\
Stage director & 0.031 \\
High school teacher & 0.033 \\
Vocational school teacher & 0.033 \\
Make-up artist & 0.035 \\
Radio director & 0.038 \\
\hline Some intermediate occupations & Probability \\
\hline \hline Dentist & 0.118 \\
Tourist guide & 0.200 \\
Programmer & 0.365 \\
Radiology technologist & 0.424 \\
Nutritionist & 0.510 \\
Cargo handler & 0.628 \\
Car Assembler & 0.694 \\
Postal clerk & 0.783 \\
Train driver & 0.874 \\
Taxi Driver & 0.954 \\
\hline Bottom 10 occupations & Probability \\
\hline \hline Packing worker & 0.972 \\
Truck driver & 0.972 \\
Hotel worker & 0.974 \\
Tourist Bus Driver & 0.974 \\
Road patrol worker & 0.974 \\
Computer-Assisted-Design operator & 0.982 \\
Data entry keyer & 0.982 \\
Industrial waste collection and transportation worker & 0.982 \\
Mail Deliverer & 0.982 \\
Computerized typesetting operator & 0.982 \\
\hline & \\
\hline
\end{tabular}


sus categories and average the values of all variables. In some cases, this approach is quite simple because occupations are similar (pharmacist, architectural engineers, childcare workers...) which led no loss of information. However, in other cases, we must insert several occupations from Career $\mathrm{Ma}$ trix in Population census categories. For example, in the category « Motor vehicle drivers $\gg$, we include taxi drivers, truck drivers, tourist bus drivers and bus drivers. For few cases, we have not any Career matrix occupation to introduce. Our solution is to compute the mean of all variables from the occupations included in the same occupation group. For example, for « house cleaning workers $»$, we average the values of the variables of building cleaning workers, waste treatment workers and other cleaning workers. Lastly, when there is no possible correspondence, we drop the corresponding occupation. We also put aside the category « Workers not classifiable by occupation $\gg$ because it contains too heterogeneous components 16 Finally, our new dataset contains $88 \%$ of employed population. By predicting probabilities of automation with this new sample, we get (i) the total number of jobs which are threatened by actual technological advance, and (ii) a detailed view by type of employment and by gender.

Frey and Osborne (2013) present their results by decomposing the total of jobs in three categories: high, middle and low risk of automation. These groups are delimited by two thresholds equal to 0.7 and 0.3 and serve as the basis for the determination of the number of jobs currently threatened by computer technology (they evaluate that $47 \%$ of US employment is at risk). If we consider the same thresholds, our results suggest that approximatively $55 \%$ of employment in Japan has a highly susceptibility to be replaced by technological equipment, namely 8 points higher than in the US (see table 2). Our predictions also state that roughly $25 \%$ of jobs are in the intermediate category and $19 \%$ can be considered as non-automatable in the next years. These estimates are consistent with the US results but the share of at risk jobs is higher. The difference of the estimated share of automatable occupations can be explained by several factors. Firstly, it is a possible that this result comes from methodological issues. Indeed, the aggregation procedure for combining Career Matrix and data from population census could lead to loss of information causing an underestimation of the number of jobs susceptible to be computerised. For example, some Population census categories contain a large number of workers such as « Other general clerical workers» or « Comprehensive clerical workers $\gg$. If we had data at a more detailed level, it would have been possible that a share of occupations in-

${ }^{16}$ It represents approximatively $6 \%$ of the employed population. 
Table 2: Share of employment by level of risk(\%)

\begin{tabular}{lccclll}
\hline Level of risk & Total & Men & Women & $\begin{array}{l}\text { Regular } \\
\text { jobs }\end{array}$ & $\begin{array}{l}\text { Temporary } \\
\text { jobs }\end{array}$ & $\begin{array}{l}\text { Part-time } \\
\text { jobs }\end{array}$ \\
\hline \hline High risk & 55.611 & 55.827 & 55.018 & 56.147 & 73.120 & 55.587 \\
Middle risk & 25.413 & 24.643 & 26.424 & 21.572 & 20.876 & 34.439 \\
Low risk & 18.977 & 19.530 & 18.559 & 22.281 & 06.004 & 09.973 \\
\hline
\end{tabular}

cluded in this group could be considered as non-computerisable which may lower the share of employment threatened. A second type of explanation is linked to the specificities of the Japanese labor market, such as the presence of differences in skills for some occupations and differences in occupational structures. Lastly, we can notice, dealing also with US data, the estimations by Pajarinen and Rouvinen (2014) give a value of $49.2 \%$ thus reducing the difference observed between the two coutries.

Beyond the determination of the share of jobs threatened by computer technology, we can also draw lessons at a more detailed level (table 2, figure 2). As shown, the vulnerability face to technological pressure is roughly similar between men and women since their respective curves are both quite close to the total curve. However, we identify a significant difference according to the type of employment. Indeed, we find evidence that the type of employment determines the exposure to ICT capital. The non-regular jobs (temporary and part-time employment) appear to be more vulnerable to computer technology at any level of probability (figure 2). This situation concerns part-time workers and is even more pronounced for temporary workers.

\subsection{Comments}

Althought this study has some methodological limitations mainly related to the lack of some variables and to the aggregation procedure ${ }^{17}$, we can draw several interesting conclusions. Our findings suggest that the diffusion of computer technology will have an important effect on employment in the next years and decades. This is caused by the fact that a growing number of economic tasks could be technically and economically performed by computer devices (they become feasible at admissible costs). From this point of view, it is expected that some occupations and jobs in Japan (and in other

\footnotetext{
${ }^{17}$ We have also used the median instead of the mean in the aggregation procedure. We obtain similar results
} 
Figure 2: Detailed results
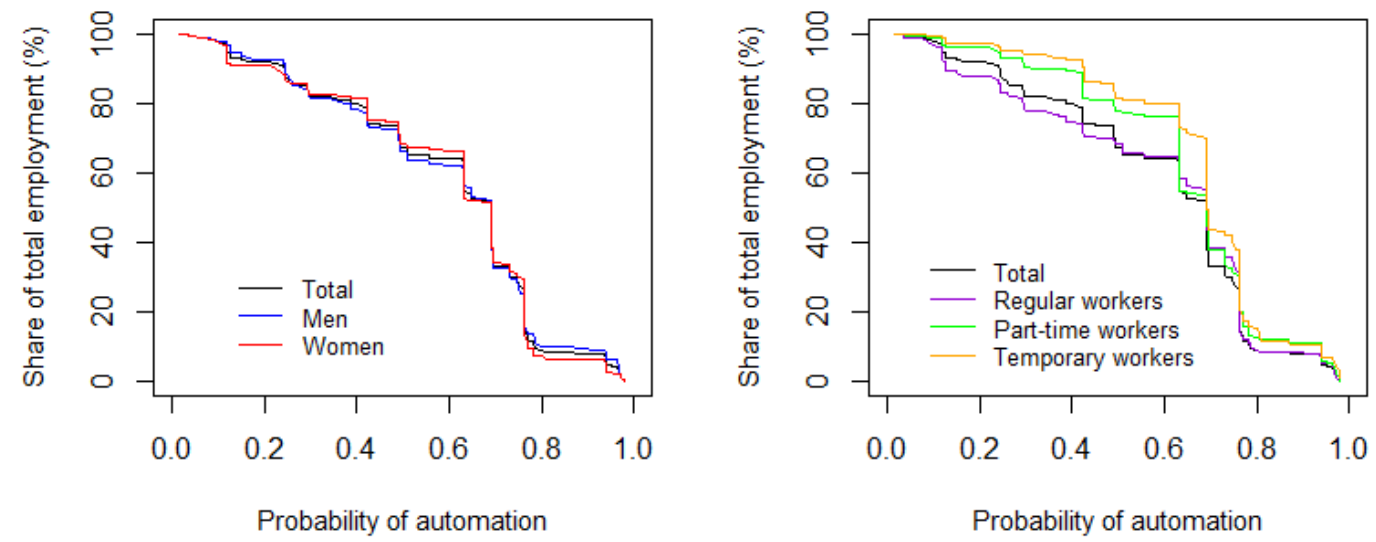

industrialized countries) will disappear in short or medium term. Although, the assessment of the exact share of jobs concerned is difficult to evaluate, our analysis shows that this share is around one half of the total employment.

These estimates are based on a technological background, and the effective realization of these predictions will finally depend on many factors technological, economic and cultural factors. A first determinant is the technological advance in terms of capacities, quality and cost offered by the future technology which will create the opportunities of investment for producers. This is indeed on this technological basis and its cost that their choices will be made. Furthermore, an important element will be the institutional and social $\ll$ response $\gg$ face to this technological wave. In this respect, the attitude of public authorities will play a key-role by promoting or not the technological diffusion. The observation of the part and recent situation suggest that they will act in favor of development and adoption of ICT. Indeed, historically, the Japanese government has supported the development of computer and robotic technologies since its beginning through the Ministry of Internal Affairs and Communication (MIC), the Ministry of Economy, Trade, and Industry (METI) or The New Energy and Industrial Technology Organization (NEDO) and continues to promote actively innovation in these fields Kitano, 2005; Lechevalier et al., 2010; Murata, 2010). One example of this continuity is the call, in May 2015, for a $\ll$ robot revolution $\gg$ by the Prime Minister Abe. These efforts are also made by firms and universities and likely to be continued due to ageing and because ICT constitute a challenge for competitiveness in a context of regional competition with China and the Republic of Korea. 
On the other hand, the availability of a technology is obviously not a sufficient condition for its adoption. It is important to emphasize that a crucial determinant of the future automation is the social acceptation of technology by producers and consumers. For instance, it must be noted that a large share of jobs which could be probably automated in the future will be through robots with an important share of humanoid robots. We further observe that there are already experimentations with the introduction of these machines in shops such as Pepper robot in Omotesando Softbank shop or the Toshiba robot (Chihira Aico) in Mitsukoshi department store. A key determinant of this kind of computerisation will be the public reception. Some scholars suggest that Japanese people are more willing to accept these new technologies than western people that might encourage automation. For example, Kaplan (2004 ${ }^{18}$ suggests that this better acceptance is due to the fact that from a western point of view, there is a clear distinction between the natural and the artificial which generates a feeling of strangeness or aversion about this kind of robot. Conversly, in the Japanese culture, there is not such distinction but rather a representation which emphasises a network of beings. This type of analysis suggests that Japanese producers and consumers may display a more positive attitude about robots, and more broadly, toward information technologies that may foster job destructions.

Another very important clarification to do about these results is that these possible destructions of jobs are not equal to future unemployment. Indeed, as pointed in section 2, the development of new technologies also supports the creation of jobs by several compensation mechanisms. Existence or importance of technological unemployment will depend on the extent of these unpredictable dynamics. One possibility is that this technological diffusion produces no unemployment, but a deep restructuring of the production apparatus. Another positive point is specific to the Japanese situation and is linked to the decline in the population and its consequence in terms of reduction of labor participation. This dynamics might offset the potential negative impact of computer technology because it is possible that computer capital will replace the individuals who enter retirement instead of the available workers. The convergence of these two phenomena might create a historical opportunity susceptible to avoid the risk of technological unemployment. On the contrary, a more pessimistic view could be supported by the fact that ICT tools seem able to perform a very large kind of tasks. The range of application seems to be unprecedented and it appears that technological limits are continually broken the barriers to capital labor/substitution. This advance

18 See also Kitano $(2005)$. 
could cause serious problems by putting forward a clear risk of technological unemployment in the short run during a transition period, but also in the long run if the compensation mechanisms are insufficient.

\section{Conclusion}

The aim of this paper is to assess the number of jobs which could be replaced by computer technology in Japan in the near future. Relying on a recent methodology, our findings suggest that $55 \%$ of actual jobs in Japan could be destroyed by computer technology diffusion and that non regular workers are more subject to this risk. The decline in the working population, the support in ICT development by public authorities, firms and universities, and the possible positive attitude about technology by Japanese people, suggest that this capital/labor substitution process could play a key role in Japan. 


\section{References}

Y. Asao. Overview of non-regular employment in japan. JILPT Report 10, JILPT, 2011.

D.H. Autor and D. Dorn. The growth of low-skill service jobs and the polarization of the us labor market. American Economic Review, 103(5): 1553,1597, August 2013. American Economic Association.

D.H. Autor, F. Levy, and R.J. Murnane. The skill content of recent technological change an empirical exploration. Quarterly Journal of Economics, 118(4):1279,1333, 2003.

L. Breiman. Bagging predictors. Machine Learning, 24(2):123,140, 1996.

L. Breiman. Random forests. Machine Learning, 45(1):5,32, 2001.

L. Breiman, J. Friedman, R. Olshen, and C. Stone. Classification and Regression Trees. Chapman \& Hall, 1984.

T.F. Bresnahan and M. Trajtenberg. General purpose technologies-engines of growth? Journal of Econometrics, 1995.

Erik Brynjolfsson and A McAfee. Race Against the Machine. 2011.

C.B. Frey and M.A. Osborne. The future of employment: How susceptible are jobs to computerization? September 2013. Oxford University Martin School.

M. Goos and A. Manning. Lousy and lovely jobs: The rising polarization of work in britain. The Review of Economics and Statistics, 89(1):118,133, February 2007. MIT Press.

M. Goos, A. Manning, and A. Salomons. Job polarization in europe. American Economic Review, 99(2):58,63, May 2009. American Economic Association.

T. Hastie, R. Tibshirani, and J. Friedman. The Elements of Statistical Learning: Prediction, Inference and Data Mining. Springer Verlag, second edition edition, 2009.

T. Ikenaga. Polarization of the japanese labor market: The adoption of it and changes in tasks contents. The Japanese Journal of Labour Studies, 584:73,90, 2009. 
T. Ikenaga and R. Kambayashi. Long-term trends in the polarization of the japanese labor market: The increase of non-routine task input and its valuation in the labor market. PIE/CIS Discussion Paper, 464, 2010.

IMF. Japan: Selected issues. IMF Country Report 13/254, International Monetary Fund, August 2013.

(IFR) International Federation of Robotics, 2014. www.ifr.org/.

(ITU) International Telecommunication Union, 2015. http://www . itu . int/ en/ITU-D/Statistics/Pages/stat/default.aspx.

(JARA) Japan Robotics Association, 2015. http://www.jara.jp/.

F Kaplan. Who is afraid of the humanoid? investigating cultural differences in the acceptance of robots. International Journal of Humanoid Robotics, $1(3): 1,16,2004$.

J.M. Keynes. Economic possibilities for our grandchildren. Saturday Evening Post, 1930.

N. Kitano. Roboethics - a comparative analysis of social acceptance of robots between the west and japan -. The Waseda Journal of Social Sciences, 6, 2005. Tokyo.

J. Koomey, S. Berard, M. Sanchez, and H. Wong. Implications of historical trends in the electrical efficiency of computing. Annals of the History of Computing, 33(3):46,54, March 2010. IEEE (Stanford University).

N. Kumaresan and K. Miyazaki. An integrated network approach to systems of innovation - the case of robotics in japan. Research Policy, 28(6): 563,585, August 1999.

S. Lechevalier, Y. Ikeda, and J. Nishimura. The effect of participation in government consortia on the r\&d productivity of firms: a case study of robot technology in japan. Economics of Innovation and New Technology, 19(8):669,692, October-November 2010.

Andy Liaw and Matthew Wiener. Classification and regression by randomforest. $R$ News, 2(3):18-22, 2002. URL http://CRAN.R-project.org/ doc/Rnews/.

K. Marx. Capital. 1867. 
E. Maurin and D. Thesmar. Changes in the functional structure of firms and the demand for skill. Journal of Labor Economics, July 2004. University of Chicago Press.

K. Murata. Lessons from the history of information system development and use in japan. Entreprises et histoire, 60:50,61, 2010.

B. Nagy, J.D. Farmer, J.E. Trancik, and J.P. Gonzales. Superexponential long-term trends in information technology. Technological Forecasting and Social Change, 78:1356,1364, 2011. doi: 10.1016/j.techfore.2011.07.006.

W.D. Nordhaus. Two centuries of productivity growth in computing. Journal of Economic History, 67:128,159, 2007.

M. Pajarinen and P. Rouvinen. Computerization threatens one third of finnish employment. ETLA Brief 22, The Research Institute of the Finish Economy (ETLA), January 2014. http://pub.etla.fi/ ETLA-Muistio-Brief-22.pdf.

P.N. Peduzzi, J. Concato, E. Kemper, T.R. Holford, and A.R. Feinstein. A simulation study of the number of events per variable in logistic regression analysis. Journal of Clinical Epidemiology, 49:1373-1379, 1996.

C. Perez. Technological revolutions and techno-economic paradigms. Cambridge Journal of Economics, 34(1):185,202, 2009.

D. Ricardo. On the Principles of Political Economy and Taxation. 1821. third edition.

N. Rosenberg and M. Trajtenberg. A general-purpose technology at work: The corliss steam engine in the late-nineteenth-century united states. The Journal of Economic History, 64(1):61,99, 2004.

F.L. Schodt. Inside the Robot Kingdom: Japan, Mechatronics and the Coming Robotopia. Kodansha International, New-York, 1988.

H.A. Simon. The steam engine and the computer: What makes technology revolutionary. Educom Bulletin, 22(1):2,5, 1987.

M.W. Spong, S. Hutchinson, and M. Vidyasagar. Robot Modeling and Control. John Wiley and sons, inc, 2012.

Ministry of Internal Affairs (MIC Statistics Bureau, 2015. http://www. stat.go.jp/index.htm. 
A. Verikas, A. Gelzinis, and M Bacauskiene. Mining data with random forests: A survey and results of new tests. Pattern Recognition, 44, 2011. doi:10.1016/j.patcog.2010.08.011.

M. Vivarelli. Innovation, employment and skills in advanced and developing countries: A survey of the literature. Technical Report IDB Publications 61058, Inter-American Development Bank, 2011.

X. Wu, V. Kumar, J.R. Quinlan, J. Ghosh, Q. Yang, H. Motoda, G.J. McLachlan, A. Ng, B. Liu, P.S. Yu, Z-H. Zhou, M. Steinbach, D.J. Hand, and D. Steinberg. Top 10 algorithms in data mining. Knowledge and Information Systems, 14(1):37, 2008.

\section{Appendix}




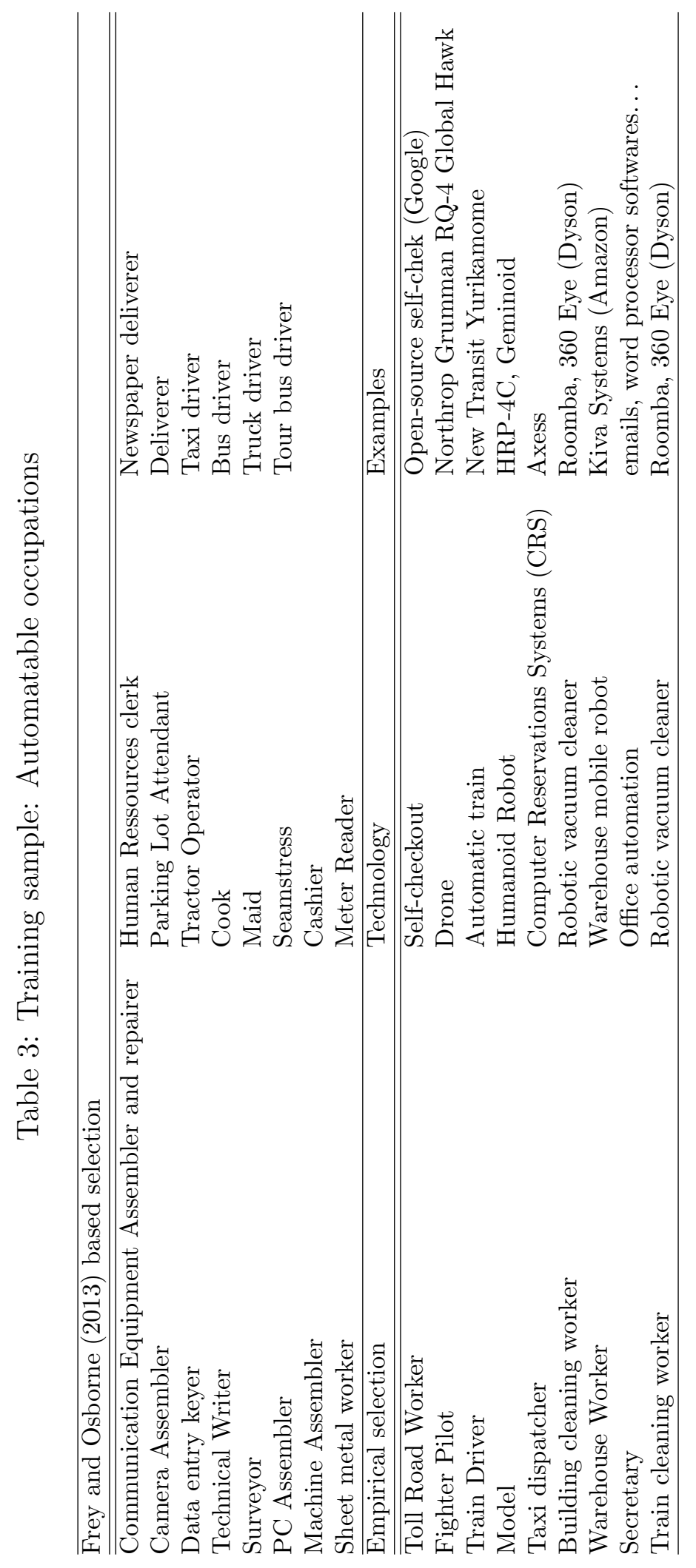


Table 4: Training sample (Non-Automatable Occupations)

\begin{tabular}{ll}
\hline \hline Professional golfer & Hairdresser \\
Professional Football Player & Prosecutor \\
Professional Baseball Player & Judge \\
Jockey & Landscape Architects \\
Professional cyclists & Lawyers \\
Sumo Wrestler & Child Counsellor \\
Sushi Cook & Surgeon \\
Chefs and Head cooks & Obstetrician, Gynaecologist \\
Childcare Workers & Pediatrician \\
Civil Engineers & Physician \\
Clergy & Physicists \\
Concierges & Plumbers \\
Dentists & Preschool teacher \\
Economist & Nurses \\
Electrical Engineers & School Nurses \\
Fashion Designers & Transport Managers \\
Flight Attendants & Waiters, Waitresses \\
Nail artist & Zoologist \\
Makeup artist & \\
\hline
\end{tabular}




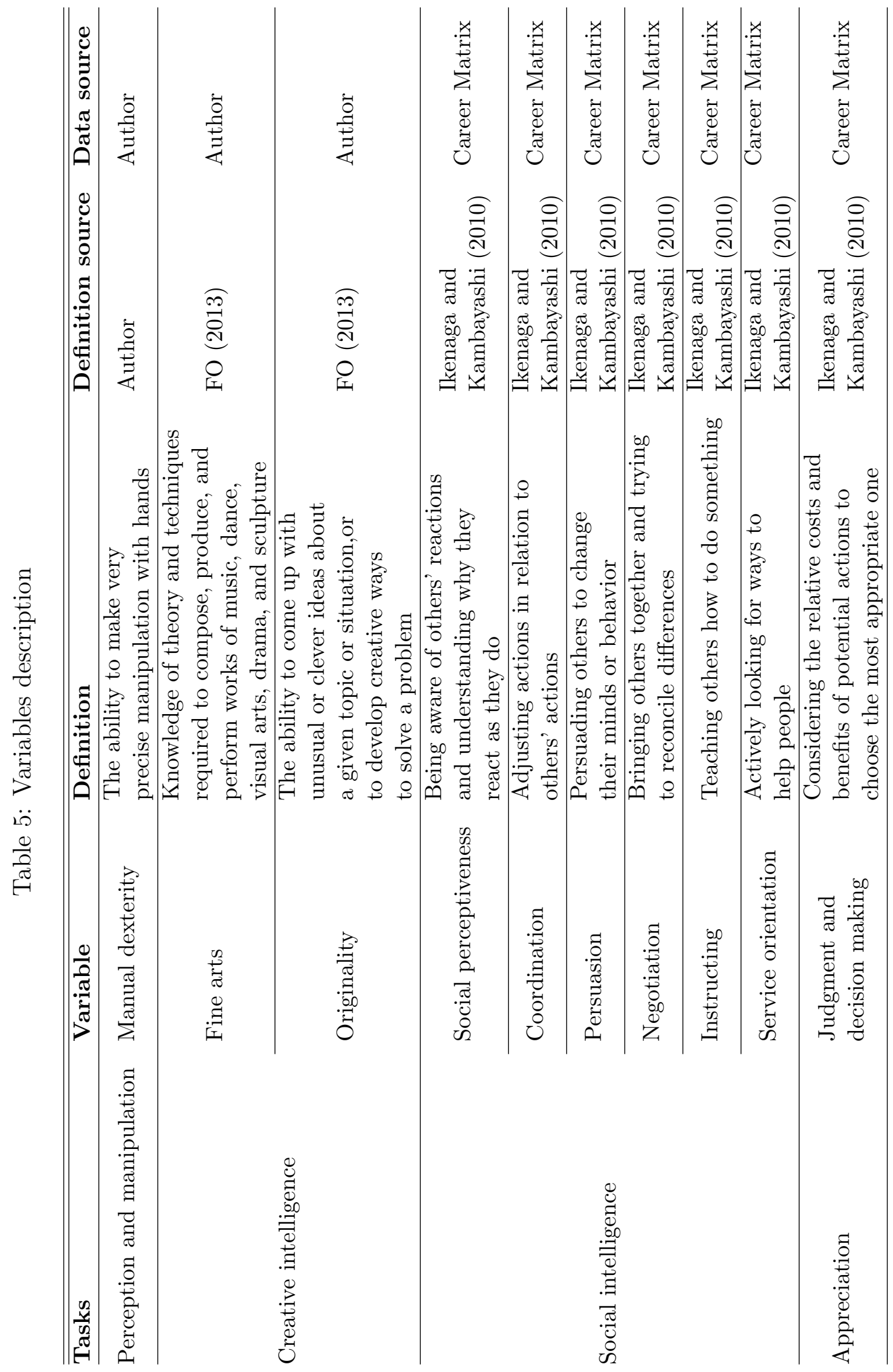


Table 6: Variable importance

\begin{tabular}{cllc}
\hline Rank & Variables & Type of tasks & \% increase in MSE \\
\hline \hline 1 & Originality & Creative intelligence & 8.06676 \\
2 & Manual dexterity & Perception and manipulation & 7.01464 \\
3 & Instructing & Social intelligence & 5.41735 \\
4 & Negotiation & Social intelligence & 4.56105 \\
5 & Persuasion & Social intelligence & 3.09784 \\
6 & Judgment and decision making & Appreciation & 2.18357 \\
7 & Fine Arts & Creative intelligence & 1.04819 \\
8 & Social perceptiveness & Social intelligence & 0.96448 \\
9 & Coordination & Social intelligence & 0.42546 \\
10 & Service orientation & Social intelligence & -2.58361 \\
\hline
\end{tabular}


Table 7: Probability of Automation by Occupation

\begin{tabular}{clc}
\hline Index & Occupation & Probability \\
\hline \hline 1 & Speech therapist & 0.014 \\
2 & Lawyer & 0.019 \\
3 & Stylist & 0.021 \\
4 & Classical Musician & 0.025 \\
5 & Theatre Decorator & 0.025 \\
6 & Stage director & 0.031 \\
7 & High school teacher & 0.033 \\
8 & Vocational school teacher & 0.033 \\
9 & Make-up artist & 0.035 \\
10 & Radio director & 0.038 \\
11 & Hairdresser & 0.043 \\
12 & Nail Artist & 0.058 \\
13 & Teacher to deaf and blind people & 0.062 \\
14 & Artistic Director & 0.068 \\
15 & Midwife & 0.071 \\
16 & Illustrator & 0.073 \\
17 & Fashion Designer & 0.073 \\
18 & Sports Instructor & 0.077 \\
19 & Ballet Dancer & 0.081 \\
20 & Junior high school teacher & 0.083 \\
21 & Floral designer & 0.084 \\
22 & Chef and Head Cook & 0.084 \\
23 & Primary school teacher & 0.084 \\
24 & Sushi chef & 0.088 \\
25 & Japanese Teacher & 0.104 \\
26 & Pre-school Teacher & 0.104 \\
27 & Interior Designer & 0.107 \\
28 & Film director & 0.107 \\
29 & Clinical engineer & 0.108 \\
30 & Ship engineer & 0.114 \\
31 & Forging engineer & 0.114 \\
32 & Fair Trade Commission employee & 0.114 \\
33 & Professional footballer & 0.118 \\
34 & Surgeon & 0.118 \\
35 & Nurse & 0.118 \\
\hline & & \\
\hline
\end{tabular}


Table 8: Probability of Automation by Occupation

\begin{tabular}{|c|c|c|}
\hline Index & Occupation & Probability \\
\hline 36 & Obstetrician, Gynaecologist & 0.118 \\
\hline 37 & Dentist & 0.118 \\
\hline 38 & Veterinary & 0.118 \\
\hline 39 & Pediatrician & 0.118 \\
\hline 40 & Physician & 0.118 \\
\hline 41 & System Engineer (project manager) & 0.124 \\
\hline 42 & Video games creator & 0.124 \\
\hline 43 & System engineer (IT consultant) & 0.124 \\
\hline 44 & System engineer (application specialist) & 0.124 \\
\hline 45 & System engineer (Software creator) & 0.124 \\
\hline 46 & Food coordinator & 0.124 \\
\hline 47 & Recording Engineer & 0.124 \\
\hline 48 & Musician & 0.127 \\
\hline 49 & Book designer & 0.129 \\
\hline 50 & Occupational therapist & 0.145 \\
\hline 51 & Retirement home instructor & 0.145 \\
\hline 52 & School Nurse & 0.145 \\
\hline 53 & Construction engineer & 0.148 \\
\hline 54 & Automobile Engineer & 0.148 \\
\hline 55 & Information engineering researcher & 0.148 \\
\hline 56 & Civil construction engineer & 0.148 \\
\hline 57 & Civil engineer & 0.148 \\
\hline 58 & Judge & 0.154 \\
\hline 59 & University and college teacher & 0.157 \\
\hline 60 & Forestry technician & 0.157 \\
\hline 61 & Clergy & 0.160 \\
\hline 62 & Psychiatrist & 0.160 \\
\hline 63 & Legal instructor & 0.177 \\
\hline 64 & Graphic Designer & 0.179 \\
\hline 65 & Stage lighting technician & 0.183 \\
\hline 66 & Pastry cook & 0.183 \\
\hline 67 & Career advisor & 0.184 \\
\hline 68 & Care Manager & 0.184 \\
\hline 69 & Family investigator & 0.184 \\
\hline 70 & Industrial counselor & 0.184 \\
\hline
\end{tabular}


Table 9: Probability of Automation by Occupation

\begin{tabular}{clc}
\hline Index & Occupation & Probability \\
\hline \hline 71 & Engine engineer & 0.184 \\
72 & Polymer chemical engineer & 0.184 \\
73 & Music teacher & 0.191 \\
74 & Medical researcher & 0.198 \\
75 & Nuclear Engineer & 0.198 \\
76 & Tourist guide & 0.200 \\
77 & Jewelry Designer & 0.201 \\
78 & System engineer (IT architect) & 0.207 \\
79 & Aerospace Engineer & 0.211 \\
80 & Metal refining engineer (iron and steel) & 0.211 \\
81 & Telecommunication engineer & 0.211 \\
82 & Fast food manager & 0.213 \\
83 & Dog Trainer & 0.213 \\
84 & Vocational training instructor & 0.213 \\
85 & Zoologist & 0.216 \\
86 & Senior volunteer & 0.217 \\
87 & Land self defense force & 0.217 \\
88 & Childcare Worker & 0.221 \\
89 & Fashion creator & 0.226 \\
90 & Glass artist & 0.236 \\
91 & System engineer (IT specialist) & 0.239 \\
92 & Electronical engineer & 0.239 \\
93 & Goldsmith & 0.241 \\
94 & Sculptor & 0.241 \\
95 & Outdoor Instructor & 0.244 \\
96 & Administrative scrivener & 0.244 \\
97 & Supermarket manager & 0.244 \\
98 & Supervisor & 0.244 \\
99 & Department store purchasing staff & 0.244 \\
100 & Medical Inspector & 0.244 \\
101 & Print sales clerk & 0.244 \\
102 & Japan Coast Guard Officer & 0.244 \\
103 & Bank branch manager & 0.244 \\
104 & Airport clerk & 0.244 \\
105 & Certified Public Accountant & 0.244 \\
\hline & & \\
& & \\
\hline
\end{tabular}


Table 10: Probability of Automation by Occupation

\begin{tabular}{|c|c|c|}
\hline Index & Occupation & Probability \\
\hline 106 & Advertising sales clerk & 0.244 \\
\hline 107 & Judicial scrivener & 0.244 \\
\hline 108 & Car salesman & 0.244 \\
\hline 109 & Director for Social Education & 0.244 \\
\hline 110 & Work and social security solicitor & 0.244 \\
\hline 111 & Trading company salesman & 0.244 \\
\hline 112 & Firefighter & 0.244 \\
\hline 113 & Life insurance sales representative & 0.244 \\
\hline 114 & Licensed tax accountant & 0.244 \\
\hline 115 & Funeral director & 0.244 \\
\hline 116 & Railway operation planning and operation management member & 0.244 \\
\hline 117 & Caseworker & 0.244 \\
\hline 118 & Welfare equipment and professional advisor & 0.244 \\
\hline 119 & Pharmacist & 0.244 \\
\hline 120 & Travel agency clerk & 0.244 \\
\hline 121 & colour coordinator & 0.251 \\
\hline 122 & Esthetician & 0.252 \\
\hline 123 & Aircraft pilot & 0.252 \\
\hline 124 & Acupuncture-moxibustion & 0.252 \\
\hline 125 & Prosthetist & 0.252 \\
\hline 126 & Bonesetter & 0.252 \\
\hline 127 & Sumo Wrestler & 0.252 \\
\hline 128 & Legal researcher & 0.257 \\
\hline 129 & Painter (art) & 0.258 \\
\hline 130 & Interior Decorator & 0.260 \\
\hline 131 & Comedian & 0.260 \\
\hline 132 & Foreign Correspondent & 0.261 \\
\hline 133 & Maritime self-defense force & 0.261 \\
\hline 134 & Prosecutor & 0.261 \\
\hline 135 & Drug enforcement officer & 0.261 \\
\hline 136 & Mangaka & 0.266 \\
\hline 137 & Fine ceramics engineer & 0.267 \\
\hline 138 & Mathematician & 0.268 \\
\hline 139 & Medical-social welfare worker & 0.274 \\
\hline 140 & Retirement home employee & 0.274 \\
\hline
\end{tabular}


Table 11: Probability of Automation by Occupation

\begin{tabular}{clc}
\hline Index & Occupation & Probability \\
\hline \hline 141 & Architectural engineer & 0.279 \\
142 & Mangaka Anime & 0.282 \\
143 & Website Creator & 0.282 \\
144 & Marketing researcher & 0.282 \\
145 & Private detective & 0.282 \\
146 & Coffeehouse clerk & 0.285 \\
147 & Bartender & 0.285 \\
148 & Hotel receptionist & 0.285 \\
149 & Screenwriter & 0.285 \\
150 & Japan Overseas Cooperation Volunteer & 0.289 \\
151 & Astronomer & 0.290 \\
152 & Power line worker & 0.295 \\
153 & House painter & 0.299 \\
154 & Jockey & 0.300 \\
155 & Economist & 0.303 \\
156 & TV reporter & 0.303 \\
157 & English teacher & 0.304 \\
158 & Juku teacher & 0.304 \\
159 & Janitor & 0.308 \\
160 & System engineer (sale) & 0.310 \\
161 & Driving school instructor & 0.315 \\
162 & Diplomat & 0.316 \\
163 & Lift Installer & 0.317 \\
164 & Electrician & 0.317 \\
165 & Plumber & 0.320 \\
166 & Livestock science researcher & 0.320 \\
167 & Livestock technician & 0.320 \\
168 & Cook (Ramen) & 0.324 \\
169 & Police officer & 0.325 \\
170 & Local legislator & 0.333 \\
171 & Precision machinery engineer & 0.337 \\
172 & Technical Writer & 0.338 \\
173 & Plant design engineer & 0.339 \\
174 & Seismologist & 0.339 \\
175 & Perfumer & 0.339 \\
\hline & & \\
\hline
\end{tabular}


Table 12: Probability of Automation by Occupation

\begin{tabular}{|c|c|c|}
\hline Index & Occupation & Probability \\
\hline$\overline{176}$ & Flight Attendant & 0.347 \\
\hline 177 & Air self-defense force & 0.354 \\
\hline 178 & Racing driver & 0.355 \\
\hline 179 & Fighter pilot & 0.355 \\
\hline 180 & Composer & 0.355 \\
\hline 181 & Go player & 0.355 \\
\hline 182 & Shogi player & 0.355 \\
\hline 183 & Japanese confectionery worker & 0.358 \\
\hline 184 & Baseball referee & 0.359 \\
\hline 185 & Ryokan manager & 0.359 \\
\hline 186 & Paratrooper & 0.359 \\
\hline 187 & International cooperation expert & 0.359 \\
\hline 188 & Small business consultant & 0.359 \\
\hline 189 & $\mathrm{TV}$, radio engineer & 0.365 \\
\hline 190 & Programmer & 0.365 \\
\hline 191 & Rolling process worker & 0.365 \\
\hline 192 & Landscape Architect & 0.365 \\
\hline 193 & Civil engineering and construction engineering researcher & 0.365 \\
\hline 194 & Prison guard & 0.371 \\
\hline 195 & Tax accountant & 0.371 \\
\hline 196 & Immigration control officer & 0.371 \\
\hline 197 & Electrical Engineer & 0.372 \\
\hline 198 & Piano Tuner & 0.373 \\
\hline 199 & Tailor (childrens' and women clothes) & 0.384 \\
\hline 200 & Taxi dispatcher & 0.387 \\
\hline 201 & Wedding staff & 0.387 \\
\hline 202 & Child Counsellor & 0.387 \\
\hline 203 & Guide-interpreter & 0.387 \\
\hline 204 & Physiotherapist & 0.387 \\
\hline 205 & Sash installer & 0.400 \\
\hline 206 & Carpenter & 0.400 \\
\hline 207 & Political scientist & 0.412 \\
\hline 208 & Aviation mechanic & 0.420 \\
\hline 209 & Biotechnology researcher & 0.420 \\
\hline 210 & Chemist & 0.420 \\
\hline
\end{tabular}


Table 13: Probability of Automation by Occupation

\begin{tabular}{clc}
\hline Index & Occupation & Probability \\
\hline \hline 211 & Fishery technician & 0.420 \\
212 & Horse trainer & 0.420 \\
213 & Ceramic engineer & 0.420 \\
214 & Agronome & 0.420 \\
215 & Physicist & 0.420 \\
216 & Cook & 0.421 \\
217 & Soba Cook & 0.421 \\
218 & Beautician & 0.421 \\
219 & Pension manager & 0.424 \\
220 & Radiology technician & 0.424 \\
221 & Waste disposal engineer & 0.424 \\
222 & Bacteriologist & 0.424 \\
223 & Food engineer & 0.424 \\
224 & Casting engineer & 0.424 \\
225 & Analytical chemistry engineer & 0.424 \\
226 & Sommelier & 0.430 \\
227 & Weather forecaster & 0.430 \\
228 & Bicycle sales clerk & 0.430 \\
229 & Pyrotechnician & 0.430 \\
230 & Poet & 0.437 \\
231 & Customer Engineer & 0.439 \\
232 & Theatre actor & 0.441 \\
233 & Voice actor & 0.441 \\
234 & Actor & 0.441 \\
235 & Jewelry maker & 0.441 \\
236 & Industrial designer & 0.445 \\
237 & International officer & 0.449 \\
238 & Shipwright & 0.449 \\
239 & Children's novelist & 0.455 \\
240 & Novelist & 0.455 \\
241 & Miner & 0.460 \\
242 & Soy sauce manufacturing worker & 0.460 \\
243 & Freelance journalist & 0.461 \\
244 & Mecatronic researcher & 0.461 \\
245 & Public relations assistant & 0.461 \\
\hline & & \\
\hline
\end{tabular}


Table 14: Probability of Automation by Occupation

\begin{tabular}{clc}
\hline Index & Occupation & Probability \\
\hline \hline 246 & Editor & 0.461 \\
247 & Photojournalist & 0.461 \\
248 & Mason (interior) & 0.463 \\
249 & Cooks (Chinese food) & 0.463 \\
250 & opérateur Computer-Assisted-Design & 0.472 \\
251 & Botanist & 0.472 \\
252 & Fine art restoration worker & 0.482 \\
253 & Tofu producer & 0.487 \\
254 & Professional golfer & 0.489 \\
255 & Production and quality control engineer & 0.489 \\
256 & Dental hygienist & 0.493 \\
257 & Chinese Masseur & 0.503 \\
258 & Chiropractor & 0.503 \\
259 & Computer equipment saleman & 0.510 \\
260 & Service station worker & 0.510 \\
261 & Game center employee & 0.510 \\
262 & Park ranger & 0.510 \\
263 & Nutritionist & 0.510 \\
264 & Breeding staff member (zoo) & 0.510 \\
265 & Parking Lot Attendant & 0.510 \\
266 & Electrical appliance salesperson & 0.510 \\
267 & Veterinary technician & 0.510 \\
268 & Amusement park worker & 0.510 \\
269 & Swordsmith & 0.537 \\
270 & Numerical controled milling machine operator & 0.537 \\
271 & Fruit grower & 0.537 \\
272 & Furniture worker & 0.537 \\
273 & Sign language interpreter & 0.547 \\
274 & Dispatcher & 0.554 \\
275 & Housing and property sales assistant & 0.554 \\
276 & Credit union liaison officer & 0.554 \\
277 & Damage service clerk & 0.554 \\
278 & Actuary & 0.557 \\
279 & Estate Agent Valuer & 0.557 \\
280 & Advertising photographer & 0.558 \\
\hline & & \\
\hline
\end{tabular}


Table 15: Probability of Automation by Occupation

\begin{tabular}{clc}
\hline Index & Occupation & Probability \\
\hline \hline 281 & Goods purchasing clerk & 0.560 \\
282 & Numerical controled turning machine operator & 0.567 \\
283 & Mould maker & 0.567 \\
284 & Cytotechnologist & 0.567 \\
285 & Electrical discharge machinist & 0.567 \\
286 & Journalist & 0.570 \\
287 & Travel writer & 0.571 \\
288 & Magazine journalist & 0.571 \\
289 & Product development staff worker & 0.572 \\
290 & Administrative clerk (country) & 0.574 \\
291 & Shoe Fitter & 0.585 \\
292 & Fruit and vegetable producer & 0.586 \\
293 & Professional Cyclist & 0.590 \\
294 & Surveyor & 0.597 \\
295 & Trade clerk & 0.598 \\
296 & Trimmer & 0.600 \\
297 & TV cameraman & 0.628 \\
298 & Cargo handler & 0.628 \\
299 & Navigator & 0.628 \\
300 & Human Ressources clerk & 0.628 \\
301 & Steelworker & 0.628 \\
302 & Power plant and substation worker & 0.628 \\
303 & Librarian & 0.630 \\
304 & Communication Equipment Assembler and Repairer & 0.630 \\
305 & Appliance repair technician & 0.630 \\
306 & Bag manufacturing worker & 0.630 \\
307 & Tailor & 0.630 \\
308 & PC Assembler & 0.630 \\
309 & Patterner & 0.630 \\
310 & Professional baseball player & 0.630 \\
311 & Miso manufacturing process worker & 0.630 \\
312 & Forensic expert & 0.630 \\
313 & Racing boat driver & 0.630 \\
314 & Joiner & 0.630 \\
315 & Dental technician & 0.630 \\
\hline & & \\
\hline
\end{tabular}


Table 16: Probability of Automation by Occupation

\begin{tabular}{|c|c|c|}
\hline Index & Occupation & Probability \\
\hline 316 & Mason & 0.630 \\
\hline 317 & Dry cleaner & 0.632 \\
\hline 318 & DIY seller & 0.632 \\
\hline 319 & Aromatherapist & 0.632 \\
\hline 320 & Kombini employee & 0.632 \\
\hline 321 & Sport articles salesperson & 0.632 \\
\hline 322 & Financial planner & 0.632 \\
\hline 323 & Bakery sales assistant & 0.632 \\
\hline 324 & Vynil, CD, salesperson & 0.632 \\
\hline 325 & Car rental clerk & 0.632 \\
\hline 326 & Curator, librarian & 0.632 \\
\hline 327 & Air traffic controller & 0.632 \\
\hline 328 & Bookshop seller & 0.632 \\
\hline 329 & Merchandise clerk & 0.632 \\
\hline 330 & Sake manufacturing process worker & 0.632 \\
\hline 331 & Sailor & 0.632 \\
\hline 332 & Zoo breeding staff & 0.632 \\
\hline 333 & Baking expert & 0.632 \\
\hline 334 & Waterproofness worker & 0.646 \\
\hline 335 & Machine assembler & 0.646 \\
\hline 336 & Violin maker & 0.651 \\
\hline 337 & Printing operator & 0.692 \\
\hline 338 & Industrial glassmaking worker & 0.692 \\
\hline 339 & Cement production operator & 0.692 \\
\hline 340 & Fish auction worker & 0.692 \\
\hline 341 & Tire manufacturing process worker & 0.692 \\
\hline 342 & Technical illustrator & 0.692 \\
\hline 343 & Ham sausage manufacturing process worker & 0.692 \\
\hline 344 & Prepress operator & 0.692 \\
\hline 345 & Wine manufacturing process worker & 0.692 \\
\hline 346 & Medical imaging equipment assembler & 0.692 \\
\hline 347 & Rice farmer & 0.692 \\
\hline 348 & Sign-board production worker & 0.692 \\
\hline 349 & Toy manufacturing process worker & 0.692 \\
\hline 350 & Footwear manufacturing worker & 0.692 \\
\hline
\end{tabular}


Table 17: Probability of Automation by Occupation

\begin{tabular}{clc}
\hline Index & Occupation & Probability \\
\hline \hline 351 & Accountancy clerck & 0.692 \\
352 & Plywood worker & 0.692 \\
353 & Lacquerware worker & 0.692 \\
354 & Drink dispenser supply worker & 0.692 \\
355 & Steel worker & 0.692 \\
356 & Lumber industry worker & 0.692 \\
357 & Binding worker & 0.692 \\
358 & Fruit and vegetable store clerk & 0.692 \\
359 & Senshokuko & 0.692 \\
360 & Fiber wholesale clerk & 0.692 \\
361 & Greengrocer, fishmonger, butcher shop owner & 0.692 \\
362 & Non-destructive testing technician & 0.692 \\
363 & Patent attorney & 0.692 \\
364 & Pipe laying worker & 0.692 \\
365 & Spinning worker & 0.692 \\
366 & Tunnel construction worker & 0.693 \\
367 & Bread production worker & 0.694 \\
368 & Integrated circuit manufacturing operator & 0.694 \\
369 & Foundry worker & 0.694 \\
370 & Tin can production worker & 0.694 \\
371 & Tile manufacturing worker & 0.694 \\
372 & Tobishoku & 0.694 \\
373 & Video rental clerk & 0.694 \\
374 & Pet shop sales assistant & 0.694 \\
375 & Pharmaceutical production employee & 0.694 \\
376 & Mover & 0.694 \\
377 & Chemical production operator & 0.694 \\
378 & Cosmetic manufacturing process worker & 0.694 \\
379 & Cook (school canteen) & 0.694 \\
380 & Carpenter & 0.694 \\
381 & Construction worker & 0.694 \\
382 & Sheet metal worker & 0.694 \\
383 & Administrative clerk (county municipality) & 0.694 \\
384 & Car Assembler & 0.694 \\
385 & Petroleum refinery operator & 0.694 \\
\hline & & \\
\hline
\end{tabular}


Table 18: Probability of Automation by Occupation

\begin{tabular}{|c|c|c|}
\hline Index & Occupation & Probability \\
\hline 386 & Railway line construction worker & 0.694 \\
\hline 387 & Dairy products worker & 0.694 \\
\hline 388 & Paving worker & 0.694 \\
\hline 389 & Textile machinery technician & 0.694 \\
\hline 390 & Frozen processed food manufacturing process worker & 0.694 \\
\hline 391 & Technical writer & 0.709 \\
\hline 392 & Optician & 0.709 \\
\hline 393 & Dealer & 0.710 \\
\hline 394 & Department store clerk & 0.732 \\
\hline 395 & Patchinko employee & 0.732 \\
\hline 396 & Orthoptist & 0.732 \\
\hline 397 & Station employee & 0.732 \\
\hline 398 & Cosmetic sales clerk & 0.732 \\
\hline 399 & Cosmetic home sales assistant & 0.732 \\
\hline 400 & Emergency Medical Technician & 0.732 \\
\hline 401 & Security guard & 0.732 \\
\hline 402 & Train conductor & 0.732 \\
\hline 403 & Bicycle manufacturing process worker & 0.740 \\
\hline 404 & Numerical controled grinding machine operator & 0.746 \\
\hline 405 & Beer manufacturing process worker & 0.746 \\
\hline 406 & Plastic product molding worker & 0.746 \\
\hline 407 & Machine center operator & 0.746 \\
\hline 408 & Plating worker & 0.746 \\
\hline 409 & Printing worker & 0.746 \\
\hline 410 & Flower producer & 0.746 \\
\hline 411 & Metal press worker & 0.746 \\
\hline 412 & Metal products inspector & 0.746 \\
\hline 413 & Metal processing inspector & 0.746 \\
\hline 414 & Metal heat treatment worker & 0.746 \\
\hline 415 & Measuring machine assembler & 0.746 \\
\hline 416 & Block worker & 0.746 \\
\hline 417 & Folding carton manufacturing process & 0.746 \\
\hline 418 & Image processing operator & 0.746 \\
\hline 419 & Industrial weaver & 0.746 \\
\hline 420 & Flight meal production worker & 0.754 \\
\hline
\end{tabular}


Table 19: Probability of Automation by Occupation

\begin{tabular}{clc}
\hline Index & Occupation & Probability \\
\hline \hline 421 & Medical technician & 0.754 \\
422 & Train cleaning worker & 0.754 \\
423 & Coastal fisherman & 0.761 \\
424 & Toy store clerk & 0.761 \\
425 & Used book salesperson & 0.761 \\
426 & Diver & 0.761 \\
427 & Building cleaning worker & 0.770 \\
428 & Boiler operator & 0.770 \\
429 & School clerk & 0.770 \\
430 & Dormitory janitor & 0.770 \\
431 & Construction machine operator & 0.770 \\
432 & Plasterer & 0.770 \\
433 & Fisheries manufacturing process worker & 0.770 \\
434 & Surveyor & 0.770 \\
435 & Forging worker & 0.770 \\
436 & Secretary & 0.781 \\
437 & Kimono dressing instructor & 0.783 \\
438 & Bellhop & 0.783 \\
439 & Waiter, Waitresse & 0.783 \\
440 & Bus tour guide & 0.783 \\
441 & Intern & 0.783 \\
442 & Postal clerk & 0.783 \\
443 & Aquaculture worker & 0.783 \\
444 & Ceramic worker & 0.783 \\
445 & Dairy farmer & 0.783 \\
446 & Toll road worker & 0.787 \\
447 & Camera Assembler & 0.788 \\
448 & Sewing machine operator & 0.788 \\
449 & Auto mechanic & 0.788 \\
450 & Welder & 0.788 \\
451 & Stenographer & 0.791 \\
452 & Photo shop employee & 0.793 \\
453 & Telecommunicator & 0.801 \\
454 & Groom & 0.810 \\
455 & Fashion salesperson & 0.812 \\
\hline & &
\end{tabular}


Table 20: Probability of Automation by Occupation

\begin{tabular}{clc}
\hline Index & Occupation & Probability \\
\hline \hline 456 & Financial analyst & 0.814 \\
457 & Flower shop clerk & 0.849 \\
458 & Bank cashier & 0.849 \\
459 & Customs officer & 0.862 \\
460 & Postal Sales Representative & 0.862 \\
461 & Unloading Worker & 0.868 \\
462 & Train driver & 0.874 \\
463 & Financial securities sales clerk & 0.937 \\
464 & Chief medical information officer & 0.939 \\
465 & Refuse Collector & 0.941 \\
466 & Department store out-of-store saleperson & 0.941 \\
467 & Meter Readers & 0.941 \\
468 & Newspaper Deliverer & 0.941 \\
469 & Warehouse worker & 0.941 \\
470 & Prepared food manufacturing process worker & 0.941 \\
471 & Cashier & 0.950 \\
472 & Golf caddie & 0.954 \\
473 & Hostess & 0.954 \\
474 & Supermarket employee & 0.954 \\
475 & Taxi Driver & 0.954 \\
476 & Home helper & 0.954 \\
477 & Reflexologist & 0.954 \\
478 & Housekeeper & 0.954 \\
479 & Receptionist & 0.954 \\
480 & Mail clerk & 0.954 \\
481 & Advertiser & 0.958 \\
482 & Ticket agency clerk & 0.958 \\
483 & Interpreter & 0.958 \\
484 & Bus Driver & 0.958 \\
485 & Medical secretary & 0.965 \\
486 & Secretary General & 0.965 \\
487 & Shop clerk (in subway station) & 0.965 \\
488 & Model & 0.966 \\
489 & Translator & 0.968 \\
490 & Packing worker & 0.972 \\
\hline & &
\end{tabular}


Table 21: Probability of Automation by Occupation

\begin{tabular}{clc}
\hline Index & Occupation & Probability \\
\hline \hline 491 & Truck driver & 0.972 \\
492 & Hotel worker & 0.974 \\
493 & Tourist Bus Driver & 0.974 \\
494 & Road patrol worker & 0.974 \\
495 & Computer-Assisted-Design operator & 0.982 \\
496 & Data entry keyer & 0.982 \\
497 & Industrial waste collection and transportation worker & 0.982 \\
498 & Mail Deliverer & 0.982 \\
499 & Computerized typesetting operator & 0.982 \\
\hline
\end{tabular}

